\title{
The effect of glutamine therapy on outcomes in critically ill patients: a meta-analysis of randomized controlled trials
}

\author{
Qi-Hong Chen ${ }^{1}$, Yi Yang ${ }^{1}$, Hong-Li He${ }^{1}$, Jian-Feng Xie', Shi-Xia Cai ${ }^{1}$, Ai-Ran Liu' ${ }^{1}$ Hua-Ling Wang ${ }^{2}$ and Hai-Bo Qiu ${ }^{1 *}$
}

\begin{abstract}
Introduction: Glutamine supplementation is supposed to reduce mortality and nosocomial infections in critically ill patients. However, the recently published reducing deaths due to oxidative stress (REDOX) trials did not provide evidence supporting this. This study investigated the impact of glutamine-supplemented nutrition on the outcomes of critically ill patients using a meta-analysis.

Methods: We searched for and gathered data from the Cochrane Central Register of Controlled Trials, MEDLINE, Elsevier, Web of Science and ClinicalTrials.gov databases reporting the effects of glutamine supplementation on outcomes in critically ill patients. We produced subgroup analyses of the trials according to specific patient populations, modes of nutrition and glutamine dosages.
\end{abstract}

Results: Among 823 related articles, eighteen Randomized Controlled Trials (RCTs) met all inclusion criteria. Mortality events among 3,383 patients were reported in 17 RCTs. Mortality showed no significant difference between glutamine group and control group. In the high dosage subgroup (above $0.5 \mathrm{~g} / \mathrm{kg} / \mathrm{d}$ ), the mortality rate in the glutamine group was significantly higher than that of the control group (relative risk (RR) 1.18; 95\% confidence interval (Cl), 1.02 to 1.38; $P=0.03$ ). In 15 trials, which included a total of 2,862 patients, glutamine supplementation reportedly affected the incidence of nosocomial infections in the critically ill patients observed. The incidence of nosocomial infections in the glutamine group was significantly lower than that of the control group (RR 0.85; $95 \% \mathrm{Cl}, 0.74$ to 0.97 ; $P=0.02)$. In the surgical ICU subgroup, glutamine supplementation statistically reduced the rate of nosocomial infections (RR 0.70; $95 \% \mathrm{Cl}, 0.52$ to $0.94 ; P=0.04$ ). In the parental nutrition subgroup, glutamine supplementation statistically reduced the rate of nosocomial infections (RR $0.83 ; 95 \% \mathrm{Cl}, 0.70$ to $0.98 ; P=0.03$ ). The length of hospital stay was reported in 14 trials, in which a total of 2,777 patients were enrolled; however, the patient length of stay was not affected by glutamine supplementation.

Conclusions: Glutamine supplementation conferred no overall mortality and length of hospital stay benefit in critically ill patients. However, this therapy reduced nosocomial infections among critically ill patients, which differed according to patient populations, modes of nutrition and glutamine dosages.

\section{Introduction}

Glutamine is the most abundant plasma and intracellular amino acid. It is known as an essential nutrient for the gastrointestinal tract during critical illness. The efflux of glutamine from the skeletal muscles serves as a carrier of nitrogen to the small intestine [1]. Increased glutamine

\footnotetext{
* Correspondence: haiboq2000@gmail.com

'Department of Critical Care Medicine, Zhong-Da Hospital, School of Medicine, Southeast University, 87 Dingjiaqiao Road, Nanjing 210009, P.R. China Full list of author information is available at the end of the article
}

use occurs during critical illness, which causes a significant glutamine deficiency and oftentimes results in an impaired immune response to infections [2]. Lower plasma and skeletal muscle glutamine levels have been associated with immune dysfunction [3] and a higher mortality rate in critically ill patients [4].

In animal studies [5], glutamine decreased gut mucosal atrophy when supplemented in the parenteral nutrition that was administered to the animals. In addition, glutamine also reduced bacterial translocation in additional animal models [6]. Some animal studies $[7,8]$ also demonstrated

\section{Biomed Central}


that glutamine supplementation improved survival in experimental models of sepsis.

In a human study [9], supplementation of enteral and parental nutrition with glutamine was observed to improve immunologic function and preserve intestinal morphology and function. In addition, glutamine supplementation may also reduce bacterial translocation [10].

Recent clinical studies [11-13] have suggested that parenteral administration of glutamine to ICU patients reduces mortality and the incidence of new infections. However, these studies were conducted in small trials, many of which were of poor quality. Recently, two large trials $[14,15]$ reported the administration of glutamine supplementation during critical illness, but did not provide similar evidence for a benefit from glutamine supplementation. Heyland et al., in the Reducing Deaths due to Oxidative Stress (REDOX) study [14], observed significantly increased in-hospital and six-month mortality rates with the use of glutamine, without reducing the nosocomial infection rate in ICU patients. The aim of this meta-analysis was to examine whether glutamine supplementation in ICU patients reduces mortality, the occurrence of nosocomial infections and the length of hospital stay.

\section{Material and methods}

\section{Inclusion criteria}

We included trials with the following features:

1. Type of studies: randomized controlled clinical trials

2. Population: adult ICU patients

3. Intervention: intravenous or enteral glutamine supplementation

4. Placebo alone or no intervention

5. The following outcomes were included: a) primary outcomes: in-hospital mortality, or if not reported, ICU/ 28-day/mortality; b) secondary outcomes: six-month mortality, nosocomial infection and length of hospital stay.

\section{Search strategy for the identification of studies}

We conducted a search of the following databases: Medline (1948 to April 2013), Elsevier, Cochrane (Central) database, Web of Science and ClinicalTrials.gov. As search terms for each database, the following keywords were used: 'glutamine' or 'glutamine dipeptides' or 'L-glutamine' or 'glutamine supplementation' and 'critical care' or 'critical patients' or 'critical ill' or 'critically ill patients' or 'critical illness' or 'serious illness' or 'seriously ill' or 'intensive care units' or 'intensive care' or 'surgical intensive care unit or 'SICU' or critical care medicine.' An additional DOCX file shows this in more detail [see Additional file 1].

\section{Study selection}

Two reviewers independently screened titles and abstracts to determine whether a particular study met the inclusion criteria. The full texts of the articles were then reviewed independently according to the inclusion and exclusion criteria. Any discrepancies were resolved by reaching a consensus on the inclusion or exclusion of a particular study following a discussion with a third reviewer.

\section{Data extraction and management}

Two reviewers independently extracted data using a standardized data extraction protocol. Any disagreements between the two reviewers were resolved by a discussion, whereby a consensus was then reached.

Some parameters, such as the mean glutamine dosage, were estimated from other available parameters. Some mean and standard deviations of the patients' length of hospital stay data were estimated according to the method described by Hozo [16].

\section{Methodological quality assessment}

The Jadad score was constructed by adding the elements of the use of the analysis and the blinded endpoint assessments. For each item from the resulting list, we assigned two points if the criterion was fulfilled, one point if the corresponding information was of insufficient detail and no points if the criterion was not fulfilled. We used the information if it met the methodological quality criteria. In addition, we assessed the risk of bias to guide sensitivity analyses and to explore the sources of heterogeneity.

\section{Statistical analysis}

We selected hospital mortality as our primary outcome measure. If this outcome was not obtained, we preferentially used the outcomes in the following order: 28-day mortality and ICU mortality. The other outcome measure was the incidence rate of nosocomial infections, mortality at six months and the length of stay.

We analyzed data from the included studies using Review Manager (Review Manager, version 5.2). We calculated a pooled risk ratio for dichotomous data and mean differences for continuous data with $95 \%$ confidence intervals (CIs). The statistical heterogeneity of the data was explored and quantified by the Mantel-Haenszel chi-square test and the $\mathrm{I}^{2}$ test. Any obvious heterogeneity was predefined as $P<0.05$ with the Mantel-Haenszel chi-square test or an $\mathrm{I}^{2}>50 \%$. A publication bias was assessed using funnel plot techniques.

\section{Subgroup meta-analyses}

Subgroup meta-analyses were performed to determine the summary effect estimates of glutamine in specific 
patient populations (medical ICU, surgical ICU or mixed ICU), effects relative to a specific dosage (above $0.5 \mathrm{~g} / \mathrm{kg} /$ day, between $0.3 \mathrm{~g} / \mathrm{kg} /$ day and $0.5 \mathrm{~g} / \mathrm{kg} /$ day, below $0.3 \mathrm{~g} / \mathrm{kg} /$ day) and the effect of the mode of nutritional supplementation (parental nutrition, enteral nutrition or a combination of the two).

\section{Results}

\section{Study location and selection}

We identified a total 823 titles and abstracts after the primary search. Of these 823 items, 245 records remained after duplicates were removed. Based on their abstracts, 223 articles were determined to be non-relevant and were, therefore, excluded. The remaining 22 articles were retrieved for an eligibility assessment, four of which were deemed to be ineligible and were, therefore, excluded (Figure 1).

\section{Summary of studies}

We included eighteen trials that compared glutamine supplementation with a placebo in ICU patients. Three trials were conducted in medical ICUs, eight in surgical ICUs and seven in mixed ICUs. High-dose glutamine (above $0.5 \mathrm{~g} / \mathrm{kg} /$ day) was used in six trials, and four trails used glutamine at doses less than $0.3 \mathrm{~g} / \mathrm{kg} /$ day; the other eight trails used glutamine at doses between $0.3 \mathrm{~g} / \mathrm{kg} /$ day and $0.5 \mathrm{~g} / \mathrm{kg} /$ day. Six studies used glutamine supplementation in which the patients were fed enterally, ten studies supplemented patients with glutamine by parental feeding, while the patients were fed using a combination of the two methods in the other two studies. An additional DOCX file shows this in more detail [see Additional file 2].

The overall description of the target population, a clear description of nosocomial infections, exclusion criteria, clinical condition and severity of the disease are summarized in Additional files [see Additional files 3, 4, 5].

\section{The impact on mortality}

The overall effect of glutamine supplementation on the mortality rates was estimated from 17 trials, which included a total of 3,383 patients (Figure 2). We detected no evidence of a publication bias after a funnel plot analysis (Figure 3), and the heterogeneity was also determined to be non-significant $\left(P=0.26, \mathrm{I}^{2}=17 \%\right)$. Hospital mortality and six-month mortality were not significantly different between glutamine group and control group (RR 1.01; 95\% CI, 0.86 to $1.19 ; P=0.87$; RR 0.97; 95\% CI, 0.79 to $1.19 ; P=0.78$ ) (Figure 2 ).

\section{Subgroup analyses of specific patient populations}

To determine the effect of glutamine on mortality in specific patient populations, we performed subgroup analyses of the trials according to whether the patients were in a medical ICU, a mixed ICU or a surgical ICU. There was a trend toward reduced mortality among patients who received glutamine as compared with patients who did not receive glutamine (10.8\% versus $14.4 \%$; RR

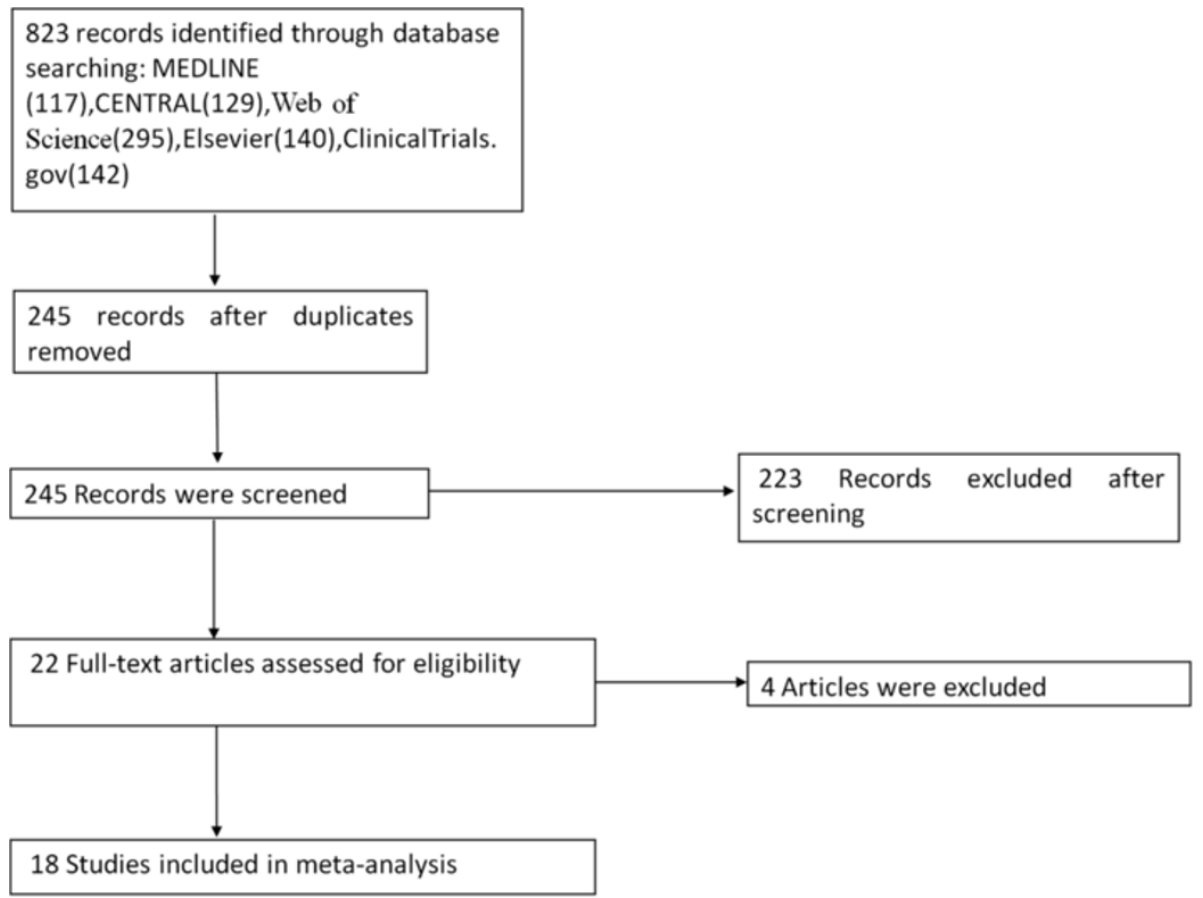

Figure 1 Flow diagram of the meta-analysis. 


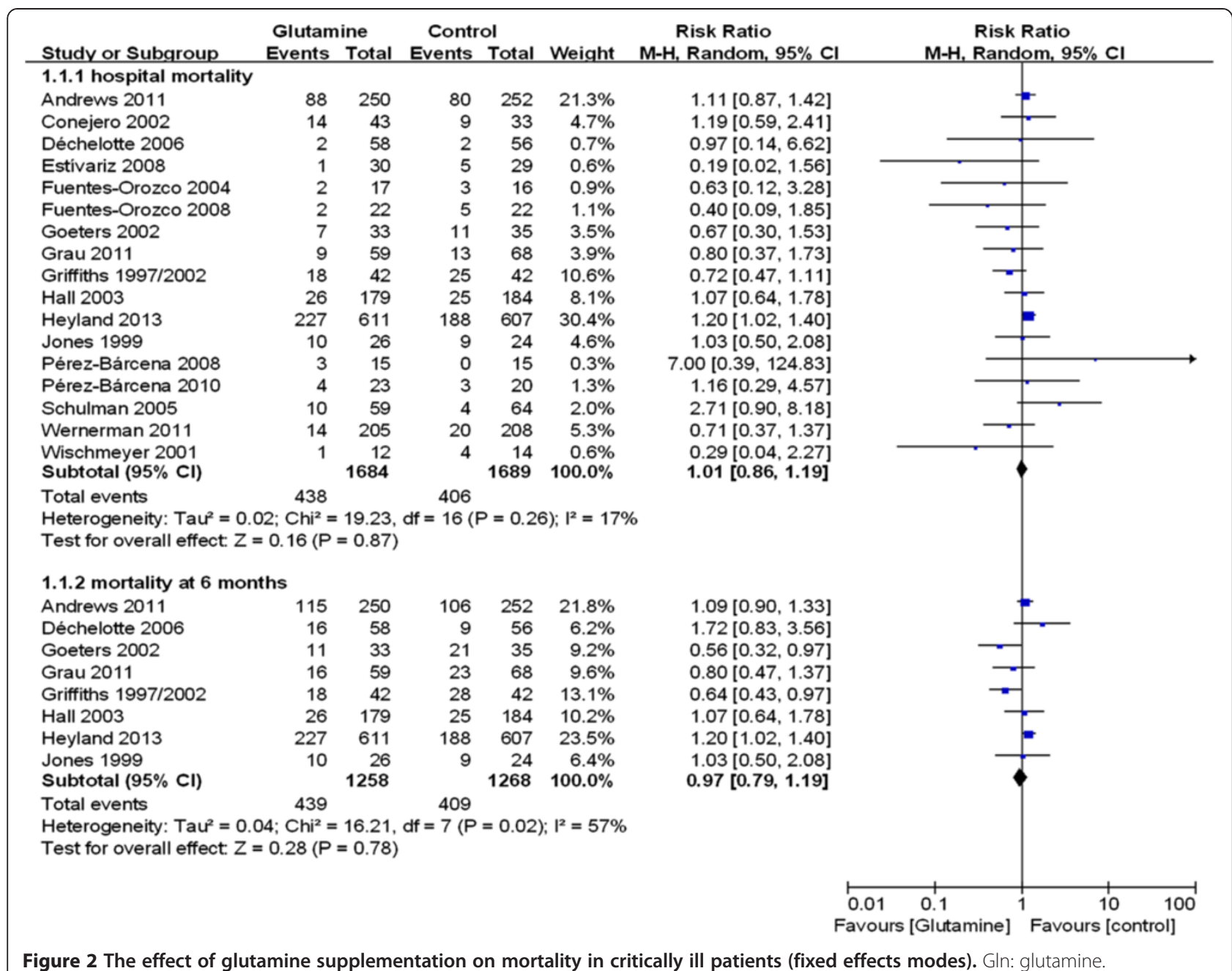

Figure 2 The effect of glutamine supplementation on mortality in critically ill patients (fixed effects modes). Gln: glutamine.

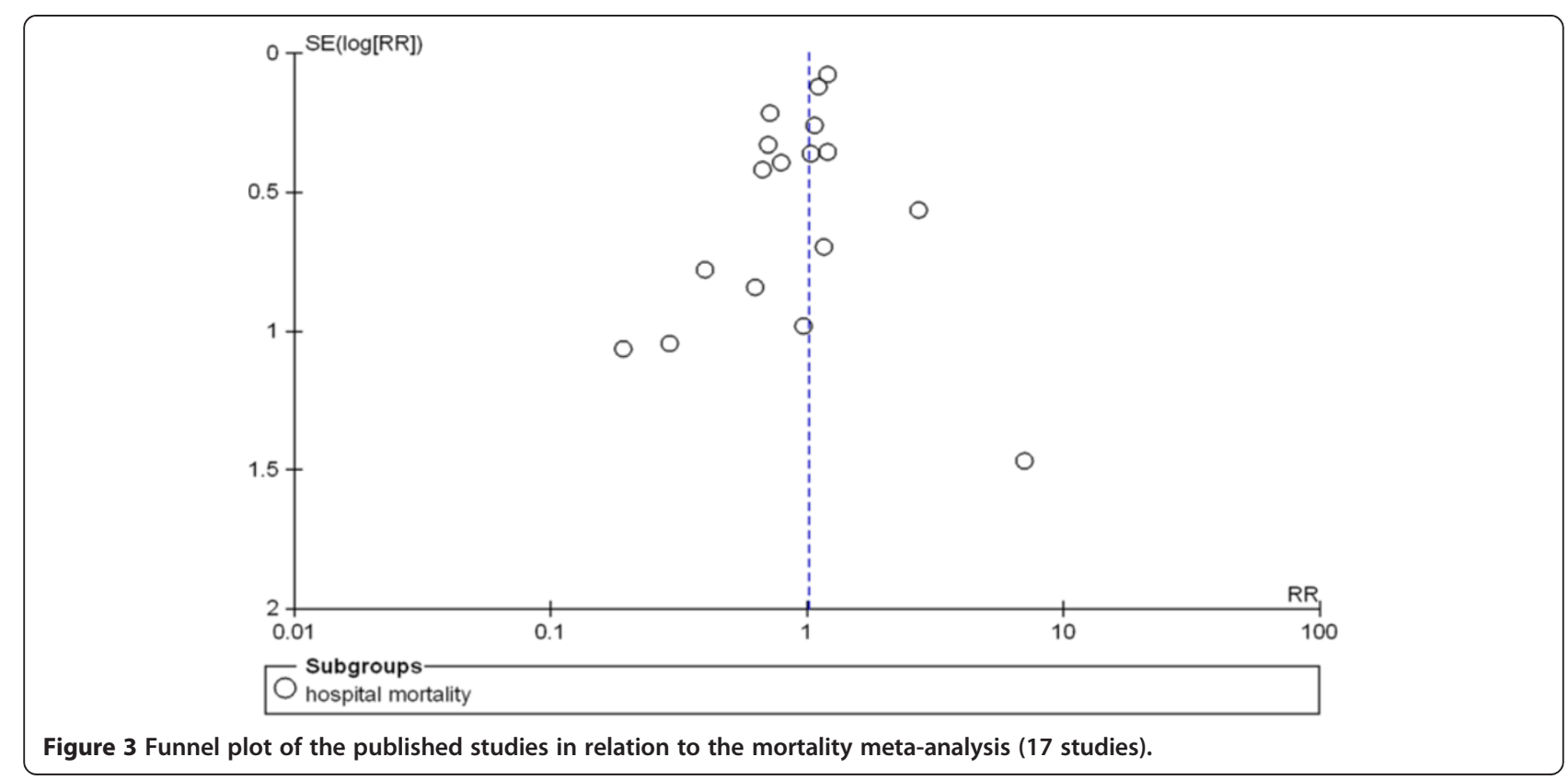


0.77 ; $95 \% \mathrm{CI}, 0.48$ to 1.23$)$, but this finding was not statistically significant $(P=0.27)$. In the medical ICU and mixed ICU subgroups, however, there was no significant difference in mortality between the glutamine group and the control group (see Additional file 2, Figure 4).

\section{Subgroup analyses of the modes of nutritional supplementation}

To explore the effect of glutamine on mortality in ICU patients with different modes of nutritional supplementation, we evaluated subgroup analyses of the trials according to whether the patients were given enteral nutrition or parental nutrition. In three subgroups, there was no significant difference in mortality between patients who received glutamine and patients who did not receive glutamine (see Additional file 2, Figure 5).

\section{A subgroup analysis of different glutamine dosages}

To determine the effect on mortality of different dosages of glutamine that were given to ICU patients, we did a subgroup analysis of the trials according to glutamine dosages (above $0.5 \mathrm{~g} / \mathrm{kg} /$ day, between $0.3 \mathrm{~g} / \mathrm{kg} /$ day and $0.5 \mathrm{~g} / \mathrm{kg} /$ day and below $0.3 \mathrm{~g} / \mathrm{kg} /$ day). In the high dosage subgroup (above $0.5 \mathrm{~g} / \mathrm{kg} /$ day), the mortality rate in the glutamine group was significantly higher than that of the control group (33.5\% versus 28.2\%; RR 1.18; 95\% CI, 1.02 to $1.38 ; P=0.03)$. In the other two subgroups, however, no difference was found in the treatment effect on mortality between the glutamine and control groups (see Additional file 2, Figure 6).

\section{Impact on nosocomial infections}

To estimate the overall effect of glutamine supplementation on the incidence rate of nosocomial infections, 15 trials, which included 2,862 patients, were evaluated (Figure 7). No evidence of a publication bias was observed following a funnel plot assessment (Figure 8), but the heterogeneity was obvious $\left(P=0.01, \mathrm{I}^{2}=51 \%\right)$. The incidence of nosocomial infections in the glutamine group was significantly lower than that of the control group (RR $0.85 ; 95 \% \mathrm{CI}, 0.74$ to $0.97 ; P=0.02$ ). We performed a subgroup analysis of the trials according to

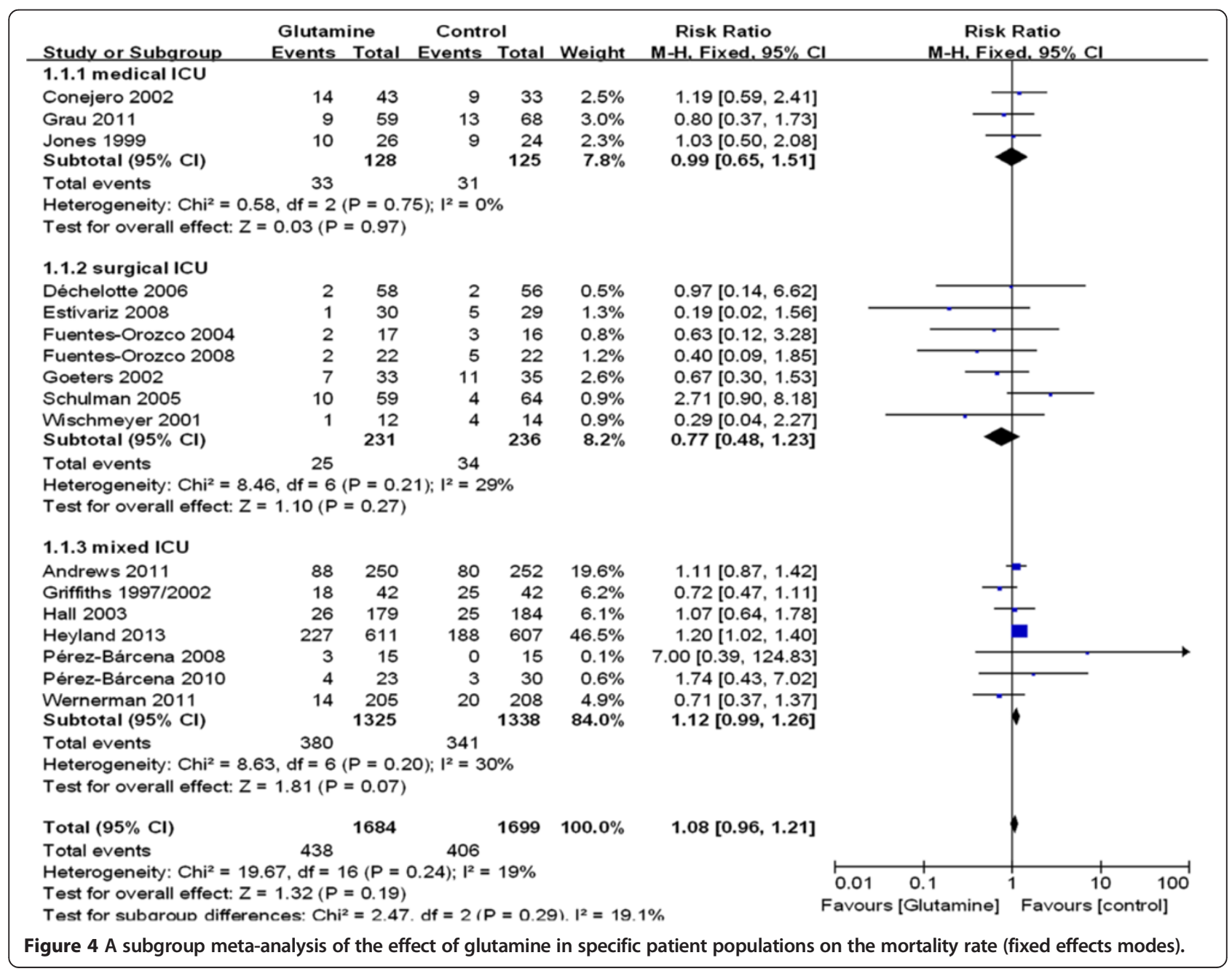




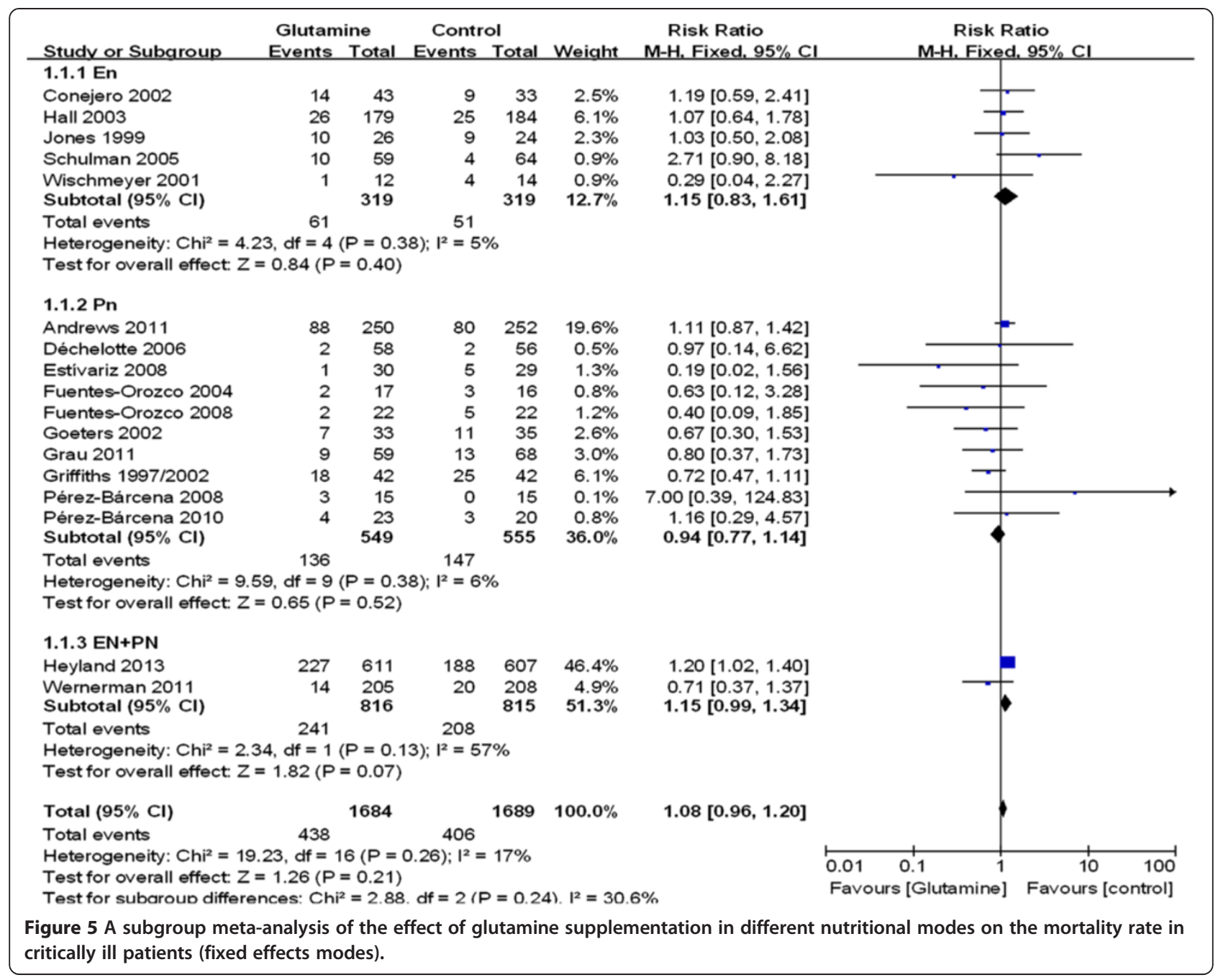

specific patient populations (medical ICU, surgical ICU or mixed ICU). In the surgical ICU subgroup, glutamine supplementation statistically reduced the rate of nosocomial infections (44.7\% versus $60.2 \%$; RR $0.70 ; 95 \% \mathrm{CI}$, 0.52 to $0.94 ; P=0.04)$. However, in the medical ICU and mixed ICU subgroups, no statistically significant difference was found between the glutamine group and the control group (Figure 9). Then we evaluated subgroup analyses of the trials according to mode of nutritional supplementation. In the parental nutrition subgroup, glutamine supplementation statistically reduced the rate of nosocomial infections (50.0\% versus 55.9\%; RR 0.83 ; 95\% CI, 0.70 to $0.98 ; P=0.03$ ) (Figure 10 ).

\section{Impact on the length of stay}

The patient length of hospital stay was reported in 14 trials that enrolled a total of 2,777 patients. We detected no evidence of a publication bias following a funnel plot assessment (Figure 11), but the heterogeneity was significantly different $\left(P<0.00001, \mathrm{I}^{2}=96 \%\right)$. No difference was found between the groups with respect to the length of hospital stay (WMD, -1.48 days; $95 \%$ CI, -3.93 to 0.98 ; $P=0.24$ ) (Figure 12).

\section{Discussion}

Similar to previous meta-analyses [17], glutamine supplementation reduced nosocomial infections among critically ill patients. However, unlike previous meta-analyses [17], we found that glutamine supplementation conferred no overall mortality benefit in critically ill patients. Furthermore, our subgroup analyses suggested that high dosage glutamine supplementation (above $0.5 \mathrm{~g} / \mathrm{kg} /$ day) significantly increased mortality in the observed critically ill patients. In addition, we did not observe a shortening of the length of hospital stay due to glutamine supplementation.

Glutamine depletion impairs gastrointestinal integrity and immunologic function and is an independent prognostic factor for poor outcomes in ICU patients [4]. Thus, the investigators of some studies that provided glutamine supplementation during critical illness expected to reduce 


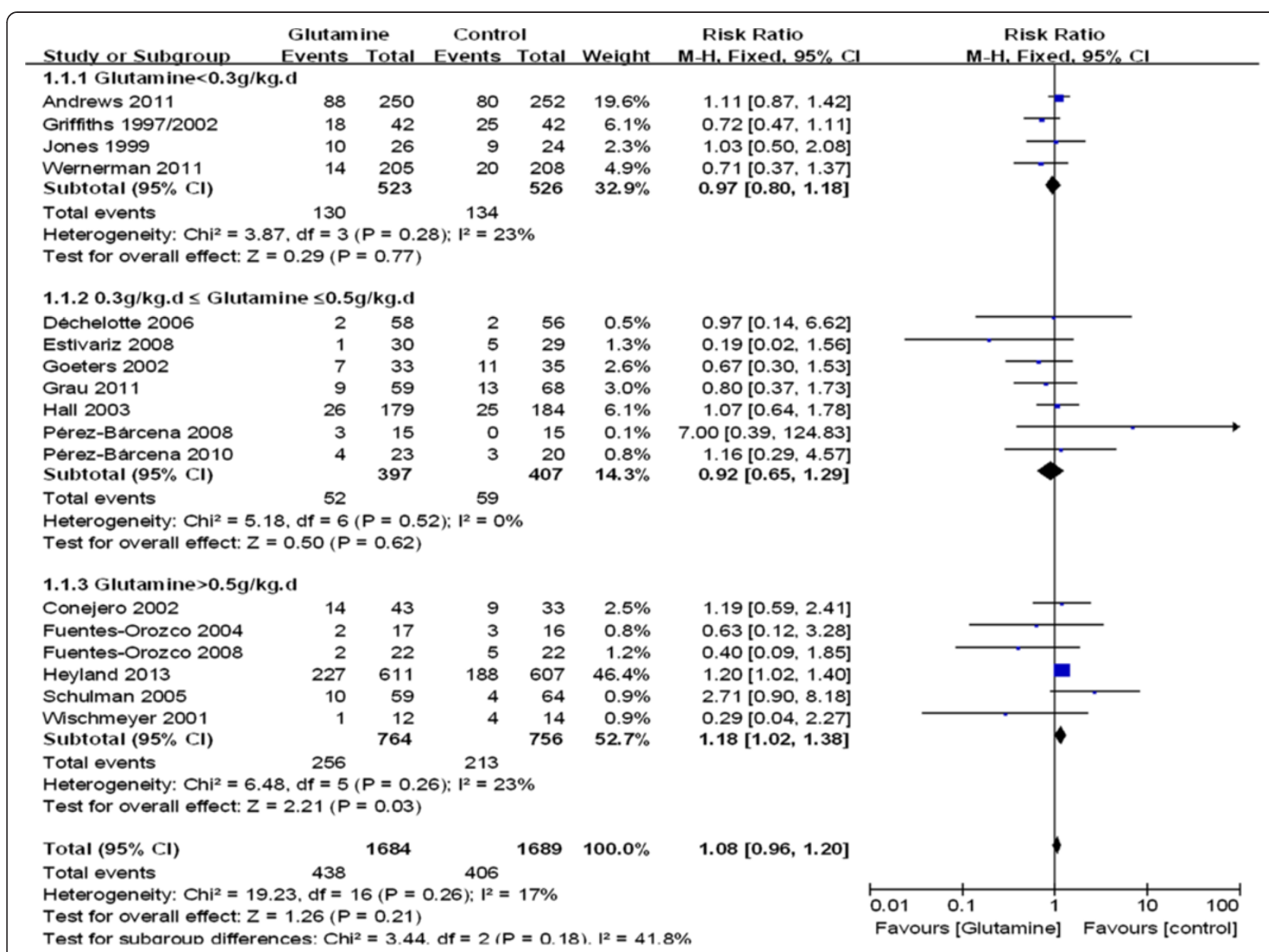

Figure 6 A subgroup meta-analysis of the different dosages of glutamine on mortality in critically ill patients (fixed effects modes).

nosocomial infection and, therefore, improve patient prognosis. In 1997, Griffiths et al. [18] showed that a glutamine-containing parental solution improved the patient six-month survival rate and reduced hospital costs in severely ill patients. Following that study, many future studies [11-13] suggested that supplementation of parental nutrition with glutamine decreased nosocomial infections following a critical illness. Additional studies [19-21] explored the prognostic role of the enteral administration of supplemental glutamine in critically ill patients; however, these findings were rather diverse and remain unclear. Therefore, it was suggested that, as a guideline [22], when parental nutrition is used in the ICU, consideration should be given to supplement it with glutamine. However, this viewpoint lacks the powerful evidence that is provided by larger trials.

Disappointingly, two larger trials showed no evidence of a benefit with glutamine as a nutritional supplement. The SIGNET study [15] was a randomized, double-blind, factorial, controlled trial that involved 502 ICU patients. Its result showed no effect on the rate of nosocomial infection incidence or on the rate of mortality when parenteral nutrition was supplemented with glutamine. The problem with the SIGNET study was giving a low dose of glutamine (20.2 g/day). The recently published REDOX study [14], the largest trial involving glutamine supplementation, suggested that glutamine supplementation was associated with an increase in mortality without any benefits for critically ill patients with multi-organ failure. However, there are problems with the REDOX study. It was unbalanced in patients with three or more organ failures and nutrition supplementation between glutamine and control group. Therefore, it was urgent to reevaluate the effect of glutamine in critically ill patients.

Many studies $[4,23,24]$ and meta-analyses $[17,25]$ of randomized trials suggest that nutritional glutamine supplementation in surgical critically ill patients may be associated with improved survival. Our subgroup meta-analyses suggested that the effect of glutamine supplementation differed by ICU setting. Patients in surgical ICUs benefited from glutamine supplementation, with the prior observation of a reduced nosocomial infection rate and a tendency for decreased mortality, in contrast to patients in medical 
ICUs and mixed ICUs. However, the exact mechanism of this benefit is unclear. One possible reason may be that surgical critically ill patients rely more on glutamine because their intestinal tracts may be impaired, and glutamine supplementation may be a primary means of obtaining glutamine during critical illness [26-28]. However, medical ICU patients [29] and some mixed ICU patients [30-32] can obtain glutamine from food in addition to glutamine supplementation. Therefore, enteral supplementation is only associated with a marginal effect on outcomes.

Reported studies [5,6] have suggested that both glutaminesupplemented parenteral nutrition and enteral nutrition may prevent bacterial translocation, but this effect may be different between the parenteral and enteral nutrition diets. We showed that the mortality rate of ICU patients was reduced when parenteral nutrition was supplemented with glutamine, but this supplementation did not provide a benefit when

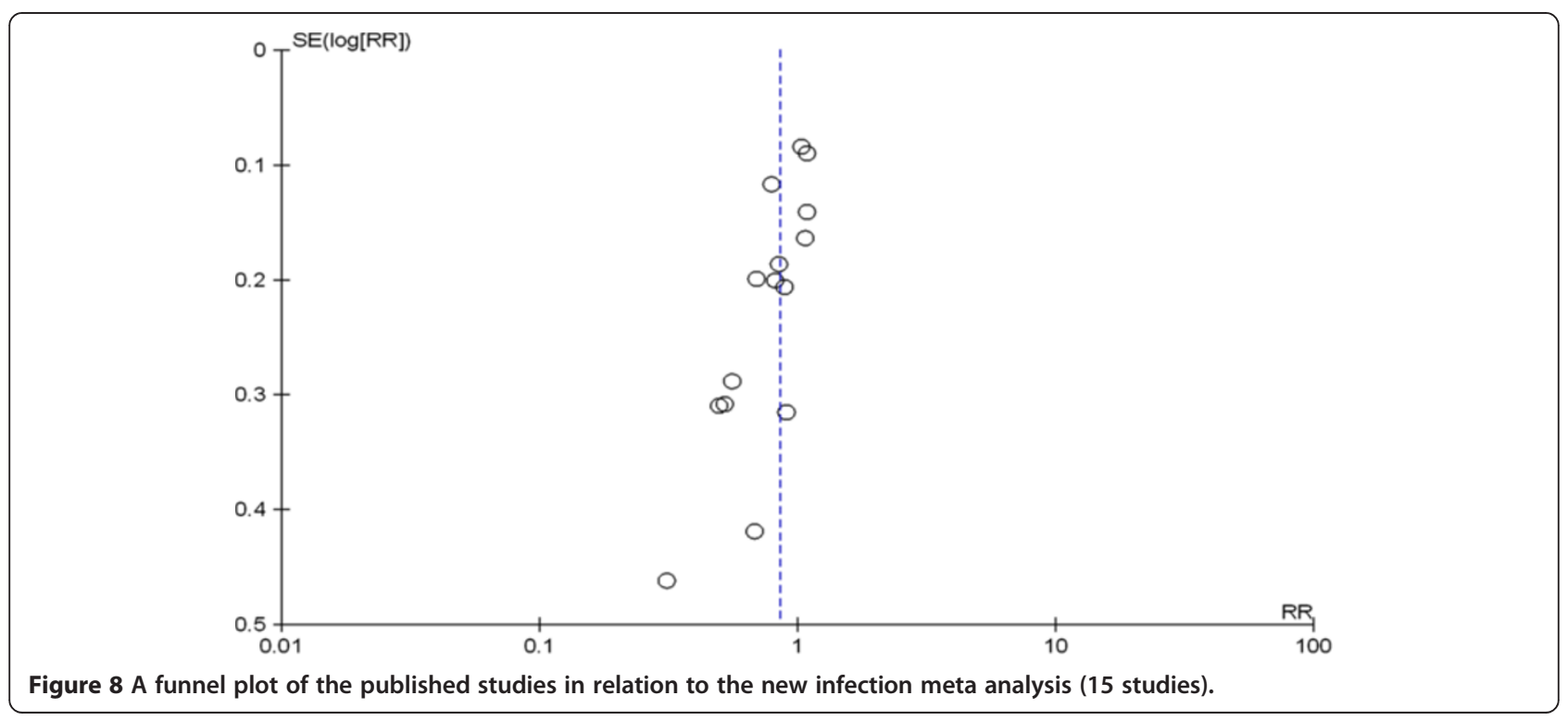




\begin{tabular}{|c|c|c|c|c|c|c|c|c|}
\hline Study or Subgroup & \multicolumn{2}{|c|}{ Glutamine } & \multicolumn{2}{|c|}{ Control } & Weight & $\begin{array}{l}\text { Risk Ratio } \\
\text { M-H. Random. } 95 \% \mathrm{Cl}\end{array}$ & \multicolumn{2}{|c|}{$\begin{array}{l}\text { Risk Ratio } \\
\text { M-H. Random. } 95 \% \mathrm{Cl}\end{array}$} \\
\hline \multicolumn{9}{|l|}{ 1.1.1 medical ICU } \\
\hline Conejero 2002 & 11 & 43 & 17 & 33 & $3.7 \%$ & $0.50[0.27,0.91]$ & & \\
\hline Grau 2011 & 24 & 59 & 31 & 68 & $6.5 \%$ & $0.89[0.60,1.34]$ & & \\
\hline Subtotal $(95 \% \mathrm{Cl})$ & & 102 & & 101 & $10.1 \%$ & $0.70[0.39,1.23]$ & & \\
\hline Total events & 35 & & 48 & & & & & \\
\hline \multicolumn{9}{|c|}{$\begin{array}{l}\text { Heterogeneity: } \mathrm{Tau}^{2}=0.10 ; \mathrm{Ch}^{2}=2.49, \mathrm{df}=1(\mathrm{P}=0.11) ; \mathrm{I}^{2}=60 \% \\
\text { Test for overall effect: } Z=1.25(P=0.21)\end{array}$} \\
\hline \multicolumn{9}{|l|}{ 1.1.2 surgical ICU } \\
\hline Déchelotte 2006 & 23 & 58 & 32 & 56 & $6.7 \%$ & $0.69[0.47,1.03]$ & & \\
\hline Estivariz 2008 & 7 & 30 & 10 & 29 & $2.3 \%$ & $0.68[0.30,1.54]$ & & \\
\hline Falcão 2004 & 5 & 10 & 10 & 10 & $3.7 \%$ & $0.52[0.29,0.96]$ & & \\
\hline Fuentes-Orozco 2004 & 4 & 17 & 12 & 16 & $1.9 \%$ & $0.31[0.13,0.77]$ & & \\
\hline Fuentes-Orozco 2008 & 9 & 22 & 16 & 22 & $4.1 \%$ & $0.56[0.32,0.99]$ & & \\
\hline Schulman 2005 & 38 & 59 & 38 & 64 & $9.4 \%$ & $1.08[0.82,1.43]$ & & \\
\hline Wischmeyer 2001 & 7 & 12 & 9 & 14 & $3.6 \%$ & $0.91[0.49,1.68]$ & & \\
\hline Subtotal $(95 \% \mathrm{Cl})$ & & 208 & & 211 & $31.7 \%$ & $0.70[0.52,0.94]$ & & \\
\hline Total events & 93 & & 127 & & & & & \\
\hline \multicolumn{9}{|c|}{ Heterogeneity: $\operatorname{Tau}^{2}=0.08: \mathrm{Chi}^{2}=13.28, \mathrm{df}=6(\mathrm{P}=0.04): \mathrm{I}^{2}=55 \%$} \\
\hline \multicolumn{9}{|c|}{$\begin{array}{l}\text { Heterogeneity: } \operatorname{Tau}^{2}=0.08 ; \mathrm{Ch}^{2}=13.28, \mathrm{df}=6(P=0.04) ; \mathrm{I}^{2}=55 \% \\
\text { Test for overall effect: } Z=2.35(P=0.02)\end{array}$} \\
\hline \multicolumn{9}{|l|}{ 1.1.3 mixed ICU } \\
\hline Andrews 2011 & 134 & 250 & 131 & 252 & $12.8 \%$ & $1.03[0.87,1.22]$ & & \\
\hline Griffiths $1997 / 2002$ & 28 & 42 & 26 & 42 & $8.3 \%$ & $1.08[0.78,1.48]$ & & \\
\hline Hall 2003 & 35 & 179 & 44 & 184 & $6.6 \%$ & $0.82[0.55,1.21]$ & $\rightarrow$ & \\
\hline Heyland 2013 & 183 & 611 & 166 & 607 & $12.4 \%$ & $1.10[0.92,1.31]$ & & \\
\hline Pérez-Bárcena 2008 & 11 & 15 & 13 & 15 & $7.3 \%$ & $0.85[0.59,1.22]$ & $\rightarrow$ & \\
\hline Pérez-Bárcena 2010 & 18 & 23 & 20 & 20 & $10.8 \%$ & $0.79[0.63,0.99]$ & & \\
\hline Subtotal $(95 \% \mathrm{Cl})$ & & 1120 & & 1120 & $58.2 \%$ & $0.96[0.85,1.09]$ & & \\
\hline \multirow{3}{*}{\multicolumn{9}{|c|}{$\begin{array}{l}\text { Total events } \\
\text { Heterogeneity: } \text { Tau }^{2}=0.01 ; \mathrm{Ch}^{2}=7.75, \mathrm{df}=5(\mathrm{P}=0.17) ; \mathrm{I}^{2}=36 \% \\
\text { Test for overall effect: } \mathrm{Z}=0.59(\mathrm{P}=0.55)\end{array}$}} \\
\hline & & & & & & & & \\
\hline & & & & & & & & \\
\hline Total $(95 \% \mathrm{Cl})$ & & 1430 & & 1432 & $100.0 \%$ & $0.85[0.74,0.97]$ & 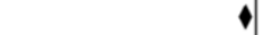 & \\
\hline Total events & 537 & & 575 & & & & & \\
\hline \multirow{2}{*}{\multicolumn{7}{|c|}{$\begin{array}{l}\text { Heterogeneity: } \mathrm{Tau}^{2}=0.03 ; \mathrm{Chi}^{2}=28.44, \mathrm{df}=14(P=0.01) ; \mathrm{I}^{2}=51 \% \\
\text { Test for overall effect: } Z=2.39(P=0.02)\end{array}$}} & $0.01 \quad 0.1$ & 100 \\
\hline & \multirow{2}{*}{\multicolumn{6}{|c|}{ Test for subaroub differences: $\mathrm{Chi}^{2}=4.63 . \mathrm{df}=2(\mathrm{P}=0.10) \cdot \mathrm{I}^{2}=56.8 \%$}} & & \\
\hline i & & & & & & & & \\
\hline
\end{tabular}

given via the gastrointestinal tract. A possible cause of this result is that those ICU patients with good intestinal function can maintain good nutrition without glutamine supplementation. Therefore, glutamine supplementation by parental feeding may be the primary method of obtaining glutamine during critical illness, because many of these patients are affected by gastrointestinal dysfunction. Furthermore, while the dosage of glutamine added by the enteral route not enough to produce a sufficient effect, it had no a favorable impact on outcome by its influence on intestinal epithelium and maintenance of gut integrity [22].

Lower plasma glutamine levels have been associated with a higher mortality rate in critically ill patients [4]; however, critical illness is not necessarily associated with a low plasma glutamine [33]. Five RCTs $[11,14,18,19,26]$ in our meta-analysis examined the plasma glutamine level; patients presented with a low baseline glutamine level $(<420 \mu \mathrm{mol} / \mathrm{L})$ in only two of these RCTs $[18,19]$. Patients with a normal plasma glutamine level cannot benefit from glutamine supplementation. Rodas et al. [34] discovered that elevated baseline levels of glutamine in the plasma (a value of $>930 \mu \mathrm{mol} / \mathrm{L}$ ) of critically ill patients was actually associated with increased mortality. Thus, high dosage glutamine supplementation caused a harmful effect, such as high urea levels [15], instead of resulting in a benefit. Our meta-analysis showed that glutamine supplementation at a dosage higher than $0.5 \mathrm{~g} / \mathrm{kg} /$ day increased mortality in ICU patients, while ICU patients may only obtain a benefit from glutamine at a dosage of between $0.3 \mathrm{~g} / \mathrm{kg} /$ day and $0.5 \mathrm{~g} / \mathrm{kg} /$ day. Glutamine supplementation at a higher dosage was used in the REDOX study, which may account for its disadvantageous role. It is, therefore, urgent to choose an optimal dose of glutamine, given the discrepancy among different studies. To solve the problem, we can monitor glutamine plasma concentration before giving glutamine to critically ill patients. It is suggested that ICU patients be given glutamine at a dosage of between $0.3 \mathrm{~g} / \mathrm{kg} /$ day and $0.5 \mathrm{~g} / \mathrm{kg} /$ day when they present with a low baseline glutamine level $(<420 \mu \mathrm{mol} / \mathrm{L})$. Appropriate glutamine plasma concentration would be a treatment target of glutamine supplementation.

Some limitations of our analysis should be noted. First, we were unable to include all relevant studies because 


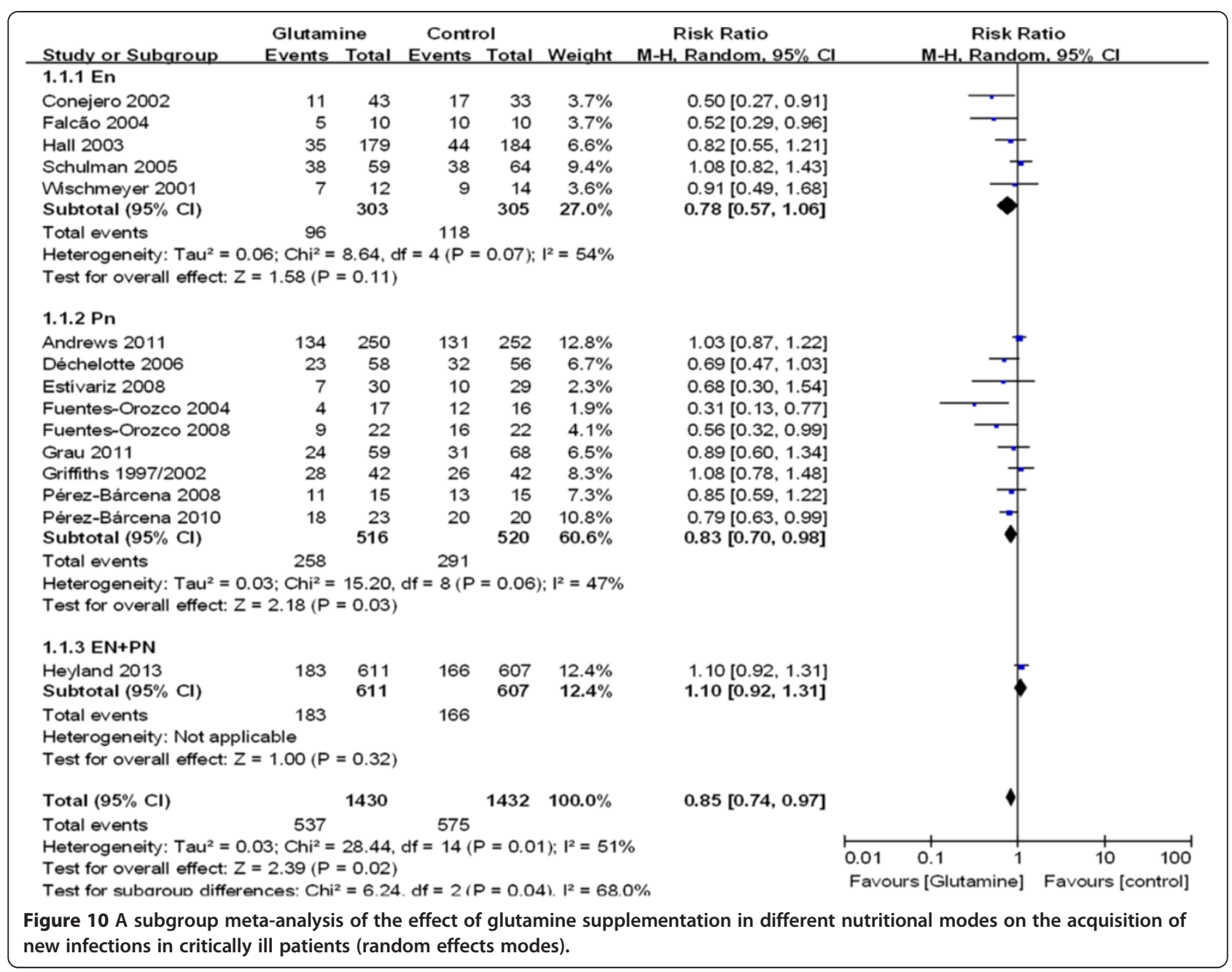

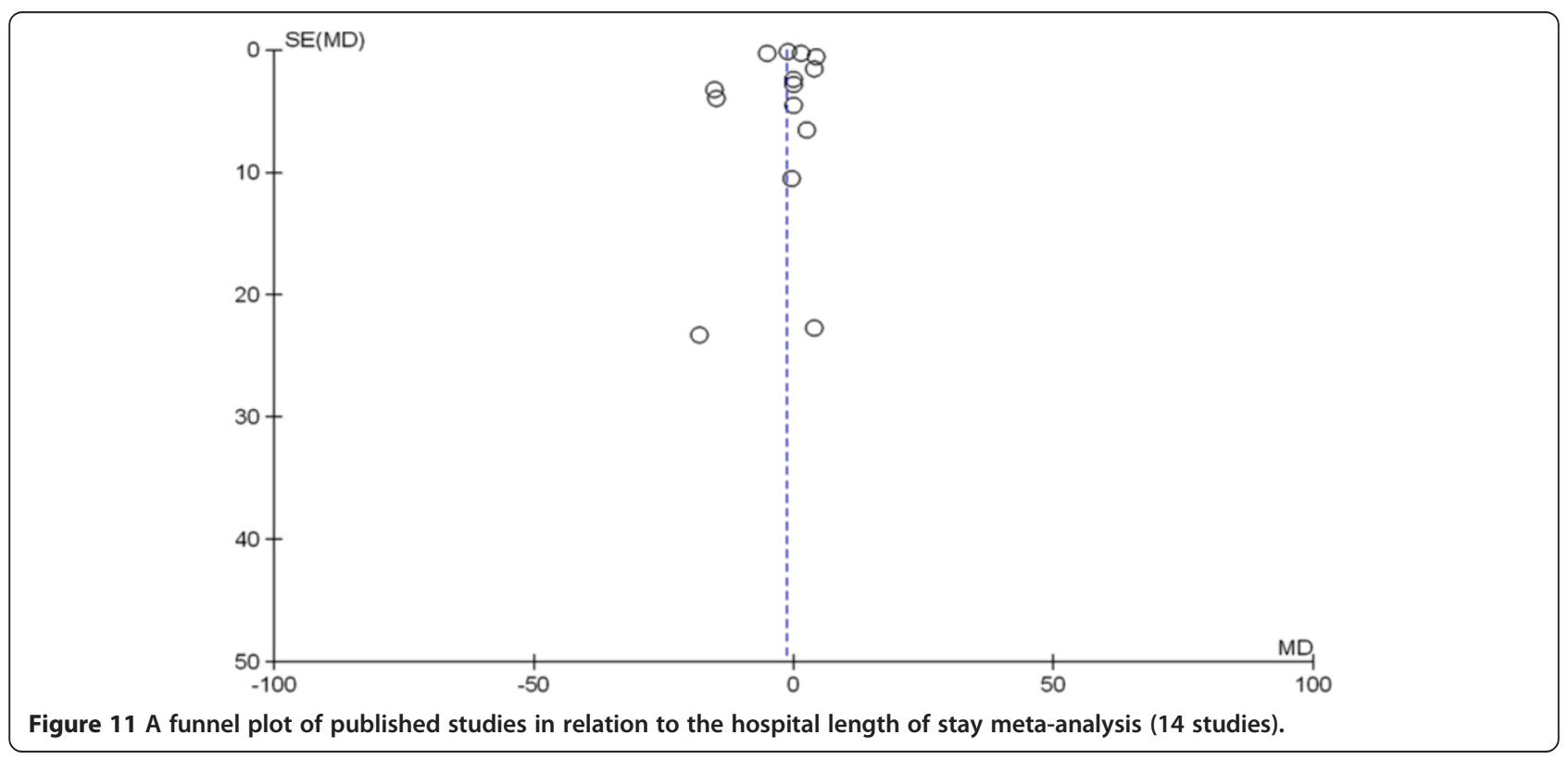




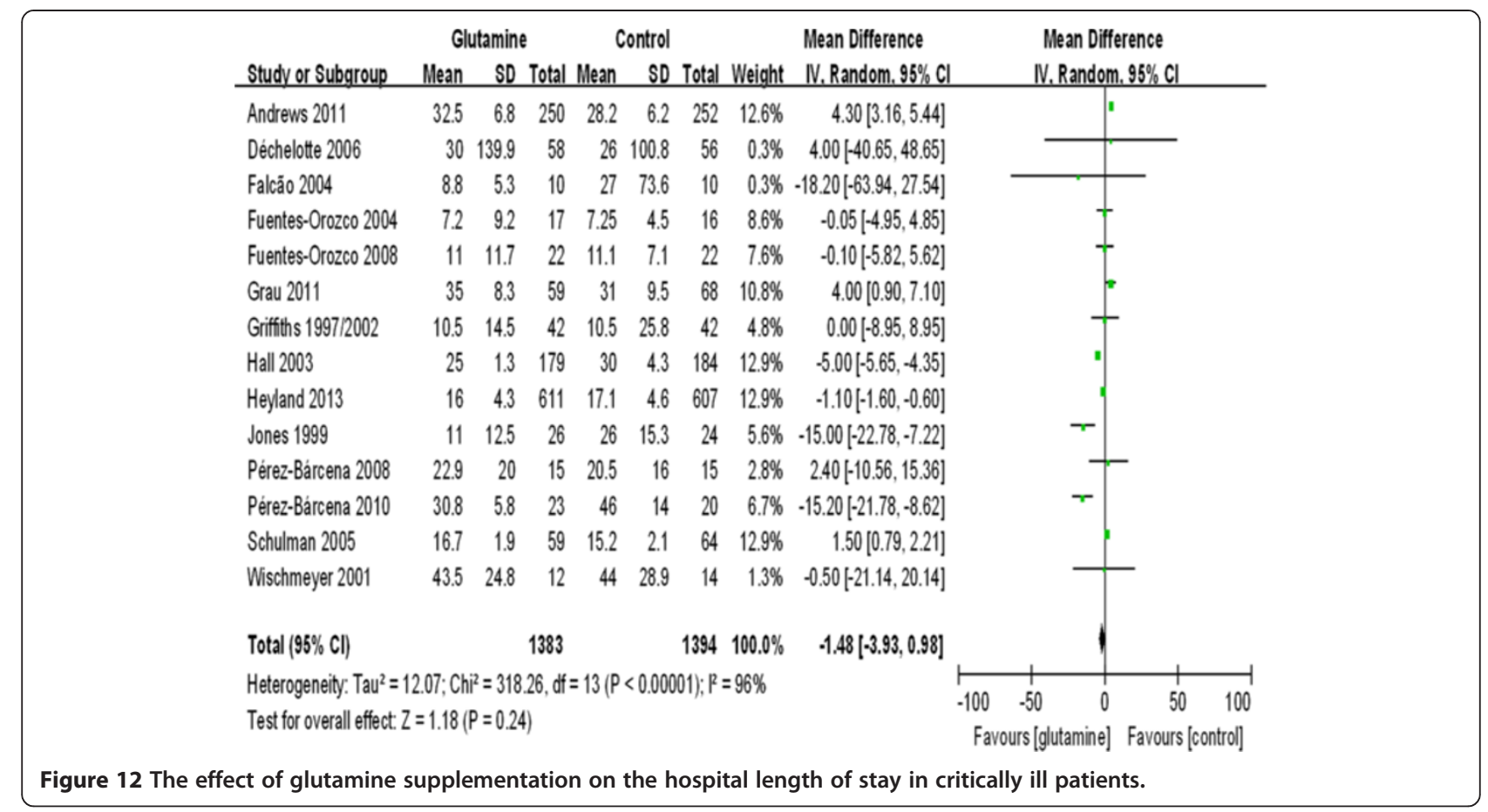

our meta-analyses could only take into account sources written in English. In addition, some published trials only reported the median and range. Using formulas, we estimated the mean and variance of the length of stay from the median, range and the size of the trial.

\section{Conclusions}

Similar to a previous meta-analysis [17], glutamine supplementation reduced nosocomial infections among critically ill patients. However, unlike previous meta-analyses [17], we found that glutamine supplementation conferred no overall mortality benefit in critically ill patients. Administration of glutamine to surgical ICU patients resulted in a significant reduction of infectious complications and may reduce mortality in these patients, which is in line with previous meta-analyses. Furthermore, our subgroup analyses suggested that high dosage glutamine supplementation (above $0.5 \mathrm{~g} / \mathrm{kg} /$ day) significantly increased mortality in the observed critically ill patients. In addition, we did not observe a shortening of the length of hospital stay due to glutamine supplementation. The discrepancies between the REDOX study and earlier evidence syntheses may be due to limitations of previous trials. However, the REDOX study is also problematic. Appropriate glutamine plasma concentration by monitoring might be a treatment target of glutamine supplementation. The effectiveness of glutamine supplementation in critically ill patients remains uncertain. Results from additional large-scale, high-quality RCTs are needed.

\section{Key messages}

- The effects of glutamine supplementation on mortality differed according to patient populations, modes of nutrition and glutamine dosages.

- Glutamine supplementation conferred no overall mortality benefit among critically ill patients.

- Glutamine supplementation reduced nosocomial infections among critically ill patients.

- Glutamine supplementation did not reduce the length of stay among critically ill patients.

- Surgical patients benefited from glutamine supplementation.

\section{Additional files}

Additional file 1: Search strategy and excluded references: the file includes electronic database search strategy and all excluded full-text articles.

Additional file 2: Summary of the studies included in the meta-analysis: this file contains a table of authors, population types, nutritional modes, glutamine dose, Jadad score and outcomes of included studies.

Additional file 3: Summary of the population included in the meta-analysis: this file contains diagnosis and comorbidities of included studies.

Additional file 4: Summary of the population included in the meta-analysis: this file contains a table of exclusion criteria and the definition of nosocomial infection of included studies.

Additional file 5: Summary of the population included in the meta-analysis: this file contains a table of comorbidities, SOFA score, glutamine plasma concentration and time to add nutrition of included studies. 


\section{Abbreviations}

MICU: medical intensive care unit; REDOX study: REducing Deaths due to OXidative Stress; SICU: surgical intensive care unit; SIGNET study: Scottish Intensive care Glutamine or seleNium Evaluative Trial; Pn: Parental nutrition; En: Enteral nutrition; WMD: Weighted Mean Difference.

\section{Competing interests}

The authors declare that they have no competing interests.

\section{Authors' contributions}

QC carried out the acquisition, analysis and interpretation of data and participated in drafting, editing and submitting the manuscript. YY contributed to the design and coordination of the study. $\mathrm{HH}$ was responsible for selecting studies. JX and SC were two reviewers screening titles and abstracts to determine whether a particular study met the inclusion criteria. AL contributed to the design, as well as the acquisition, analysis and interpretation of data. HW contributed to study analysis and interpretation of data, and HQ was responsible for conception and design, and revising the manuscript for important intellectual content. All authors read and approved the final manuscript.

\section{Acknowledgements}

Contract grant sponsor: National Natural Science Foundations of China; Contract grant numbers; 81070049, 81000828, 81170057.

\section{Author details}

${ }^{1}$ Department of Critical Care Medicine, Zhong-Da Hospital, School of Medicine, Southeast University, 87 Dingjiaqiao Road, Nanjing 210009, P.R. China ${ }^{2}$ Department of Critical Care Medicine, Su-Bei Hospital of Jiangsu Provience \& Clinical Medical School, Yangzhou University, Yangzhou, Jiangsu, P.R. China.

Received: 8 July 2013 Accepted: 27 December 2013

Published: 9 January 2014

\section{References}

1. Lacey JM, Wilmore DW: Is glutamine a conditionally essential amino acid? Nutr Rev 1990, 48:297-309.

2. Long CL, Borghesi L, Stahl R, Clark JA, Geiger JW, DiRienzo DB, Weis JK, Laws $H L$, Blakemore WS: Impact of enteral feeding of a glutamine-supplemented formula on the hypoaminoacidemic response in trauma patients. J Trauma 1996, 40:97-102.

3. Parry-Billings M, Evans J, Calder PC, Newsholme EA: Does glutamine contribute to immunosuppression after major burns? Lancet 1990, 336:523-525.

4. Oudemans-van Straaten HM, Bosman RJ, Treskes M, van der Spoel HJ, Zandstra DF: Plasma glutamine depletion and patient outcome in acute ICU admissions. Intensive Care Med 2001, 27:84-90.

5. Khan J, liboshi Y, Cui L, Wasa M, Sando K, Takagi Y, Okada A: Alanyl-glutaminesupplemented parenteral nutrition increases luminal mucus gel and decreases permeability in the rat small intestine. JPEN J Parenter Enteral Nutr 1999, 23:24-31.

6. Gianotti L, Alexander JW, Gennari R, Pyles T, Babcock GF: Oral glutamine decreases bacterial translocation and improves survival in experimental gut-origin sepsis. JPEN J Parenter Enteral Nutr 1995, 19:69-74.

7. Inoue Y, Grant JP, Snyder PJ: Effect of glutamine-supplemented intravenous nutrition on survival after Escherichia coli-induced peritonitis. JPEN J Parenter Enteral Nutr 1993, 17:41-46.

8. Ardawi MS: Effect of glutamine-enriched total parenteral nutrition on septic rats. Clin Sci (Lond) 1991, 81:215-222.

9. Saito H, Furukawa S, Matsuda T: Glutamine as an immunoenhancing nutrient. JPEN J Parenter Enteral Nutr 1999, 23:S59-S61.

10. Buchman AL: Glutamine: is it a conditionally required nutrient for the human gastrointestinal system? J Am Coll Nutr 1996, 15:199-205.

11. Estívariz CF, Griffith DP, Luo M, Szeszycki EE, Bazargan N, Dave N, Daignault NM, Bergman GF, McNally T, Battey CH, Furr CE, Hao L, Ramsay JG, Accardi CR, Cotsonis GA, Jones DP, Galloway JR, Ziegler TR: Efficacy of parenteral nutrition supplemented with glutamine dipeptide to decrease hospital infections in critically ill surgical patients. JPEN J Parenter Enteral Nutr 2008, 32:389-402.

12. Pérez-Bárcena J, Regueiro V, Marsé P: Glutamine as a modulator of the immune system of critical care patients: effect on Toll-like receptor expression. A preliminary study. Nutrition 2008, 24:522-527.
13. Fuentes-Orozco C, Cenvantes-Guevara G, Muciño-Hernández I, López-Ortega A, Ambriz-González G, Gutiérrez-de-la-Rosa JL, Gómez-Herrera E, Hermosillo-Sandoval JM, González-Ojeda A: L-alanyl-L-glutamine-supplemented parenteral nutrition decreases infectious morbidity rate in patients with severe acute pancreatitis. JPEN J Parenter Enteral Nutr 2008, 32:403-411.

14. Heyland D, Muscedere J, Wischmeyer PE, Cook D, Jones G, Albert M, Elke G, Berger MM, Day AG, Canadian Critical Care Trials Group: A randomized trial of glutamine and antioxidants in critically ill patients. N Engl J Med 2013, 368:1489-1497.

15. Andrews PJ, Avenell A, Noble DW, Campbell MK, Croal BL, Simpson WG Vale LD, Battison CG, Jenkinson DJ, Cook JA, Scottish Intensive care Glutamine or seleNium Evaluative Trial Trials Group: Randomised trial of glutamine, selenium, or both, to supplement parenteral nutrition for critically ill patients. BMJ 2011, 342:d1542

16. Hozo SP, Djulbegovic B, Hozo I: Estimating the mean and variance from the median, range, and the size of a sample. BMC Med Res Methodol 2005, 5:13.

17. Bollhalder L, Pfeil AM, Tomonaga Y, Schwenkglenks M: A systematic literature review and meta-analysis of randomized clinical trials of parenteral glutamine supplementation. Clin Nutr 2013, 32:213-223.

18. Griffiths RD, Jones C, Palmer TE: Six-month outcome of critically ill patients given glutamine-supplemented parenteral nutrition. Nutrition 1997, 13:295-302.

19. Jones C, Palmer TE, Griffiths RD: Randomized clinical outcome study of critically ill patients given glutamine-supplemented enteral nutrition. Nutrition 1999, 15:108-115.

20. Conejero R, Bonet A, Grau T, Esteban A, Mesejo A, Montejo JC, López J, Acosta JA: Effect of a glutamine-enriched enteral diet on intestinal permeability and infectious morbidity at 28 days in critically ill patients with systemic inflammatory response syndrome: a randomized, single-blind, prospective, multicenter study. Nutrition 2002, 18:716-721.

21. Wischmeyer PE, Lynch J, Liedel J, Wolfson R, Riehm J, Gottlieb L, Kahana M: Glutamine administration reduces Gram-negative bacteremia in severely burned patients: a prospective, randomized, double-blind trial versus isonitrogenous control. Crit Care Med 2001, 29:2075-2080.

22. McClave SA, Martindale RG, Vanek WW, McCarthy M, Roberts P, Taylor B, Ochoa JB, Napolitano L, Cresci G, A.S.P.E.N. Board of Directors, American College of Critical Care Medicine, Society of Critical Care Medicine: Guidelines for the Provision and Assessment of Nutrition Support Therapy in the Adult Critically III Patient: Society of Critical Care Medicine (SCCM) and American Society for Parenteral and Enteral Nutrition (A.S.P.E.N.). JPEN J Parenter Enteral Nutr 2009, 33:277-316.

23. Schulman AS, Willcutts KF, Claridge JA, Evans HL, Radigan AE, O'Donnell KB, Camden JR, Chong TW, McElearney ST, Smith RL, Gazoni LM, Farinholt HM, Heuser CC, Lowson SM, Schirmer BD, Young JS, Sawyer RG: Does the addition of glutamine to enteral feeds affect patient mortality? Crit Care Med 2005, 33:2501-2506.

24. Fuentes-Orozco C, Anaya-Prado R, González-Ojeda A, Arenas-Márquez H, Cabrera-Pivaral C, Cervantes-Guevara G, Barrera-Zepeda LM: L-alanyl-Lglutamine-supplemented parenteral nutrition improves infectious morbidity in secondary peritonitis. Clin Nutr 2004, 23:13-21.

25. Marik PE, Zaloga GP: Immunonutrition in critically ill patients: a systematic review and analysis of the literature. Intensive Care Med 2008, 34:1980-1990.

26. Goeters C, Wenn A, Mertes N, Wempe C, Van Aken H, Stehle P, Bone HG: Parenteral L-alanyl-L-glutamine improves 6-month outcome in critically ill patients. Crit Care Med 2002, 30:2032-2037.

27. Hall JC, Dobb G, Hall J, de Sousa R, Brennan L, McCauley R: A prospective randomized trial of enteral glutamine in critical illness. Intensive Care Med 2003, 29:1710-1716.

28. Falcão de Arruda IS, de Aguilar-Nascimento JE: Benefits of early enteral nutrition with glutamine and probiotics in brain injury patients. Clin Sci (Lond) 2004, 106:287-292.

29. Déchelotte $P$, Hasselmann M, Cynober L, Allaouchiche B, Coëffier M, Hecketsweiler B, Merle V, Mazerolles M, Samba D, Guillou YM, Petit J, Mansoor O, Colas G, Cohendy R, Barnoud D, Czernichow P, Bleichner G: $\mathrm{L}$-alanyl-L-glutamine dipeptide-supplemented total parenteral nutrition reduces infectious complications and glucose intolerance in critically ill patients: the French controlled, randomized, double-blind, multicenter study. Crit Care Med 2006, 34:598-604.

30. Pérez-Bárcena J, Crespí C, Regueiro V, Marsé P, Raurich JM, Ibáñez J, García de Lorenzo-Mateos A, Bengoechea JA: Lack of effect of glutamine 
administration to boost the innate immune system response in trauma patients in the intensive care unit. Crit Care 2010, 14:R233.

31. Wernerman J, Kirketeig T, Andersson B, Berthelson H, Ersson A, Friberg H, Guttormsen AB, Hendrikx S, Pettilä V, Rossi P, Sjöberg F, Winsö O,

Scandinavian Critical Care Trials Group: Scandinavian glutamine trial: a pragmatic multi-centre randomised clinical trial of intensive care unit patients. Acta Anaesthesiol Scand 2011, 55:812-818.

32. Grau T, Bonet A, Miñambres E, Piñeiro L, Irles JA, Robles A, Acosta J, Herrero I, Palacios V, Lopez J, Blesa A, Martínez P, Metabolism, Nutrition Working Group, SEMICYUC, Spain: The effect of L-alanyl-L-glutamine dipeptide supplemented total parenteral nutrition on infectious morbidity and insulin sensitivity in critically ill patients. Crit Care Med 2011, 39:1263-1268.

33. Heyland DK, Dhaliwal R: Role of glutamine supplementation in critical illness given the results of the REDOXS study. JPEN J Parenter Enteral Nutr 2013, 37:442-443.

34. Rodas PC, Rooyackers O, Hebert C, Norberg $\AA$, Wernerman J: Glutamine and glutathione at ICU admission in relation to outcome. Clin Sci (Lond) 2012, 122:591-597.

doi:10.1186/cc13185

Cite this article as: Chen et al:: The effect of glutamine therapy on

outcomes in critically ill patients: a meta-analysis of randomized controlled trials. Critical Care 2014 18:R8.

\section{Submit your next manuscript to BioMed Central and take full advantage of:}

- Convenient online submission

- Thorough peer review

- No space constraints or color figure charges

- Immediate publication on acceptance

- Inclusion in PubMed, CAS, Scopus and Google Scholar

- Research which is freely available for redistribution 